\title{
Evaluation of a poison prevention lesson for kindergarten and third grade students
}

\author{
Karen D Liller, Janice Craig, Nancy Crane, Robert J McDermott
}

\begin{abstract}
Objectives-The purpose of this study was to evaluate the MORE HEALTH poison prevention lesson that is given to kindergarten and third grade students in Hillsborough County, Florida. The lesson reaches approximately 6000 students per year.

Methods-The evaluation was based on a post-test only control group design. Three schools were chosen as evaluation sites and three served as control settings. Students were administered a previously tested, age appropriate questionnaire that addressed the goals of the poison lessons. In addition, a survey was developed for intervention school parents to determine their poison prevention practices.

Results-One hundred ninety four intervention schoolchildren and 184 control schoolchildren completed the study. Children in the intervention schools consistently answered more questions correctly than those in the control schools. The parent survey showed that the majority have homes that are safe from poisons, although fewer than $50 \%$ said they had syrup of ipecac in their homes.

Conclusions-These results show that key concepts related to poison prevention can be communicated effectively to primary school students and parents report having homes safe from many poisons.

(Injury Prevention 1998;4:218-221)
\end{abstract}

Keywords: poison prevention; elementary schools; evaluation

Nationally, children's deaths from poisonings have declined dramatically due to many factors such as the development of poison control centers and improved emergency care, child resistant packaging, and reduced use of poisonous substances and/or product reformulation. ${ }^{1}$ Since 1972 in the United States, there has been an $84 \%$ decline in deaths due to household chemicals and a $98 \%$ decline in deaths due to aspirin products among children younger than 5 years of age. ${ }^{2}$ Even though childhood deaths have declined, children are still exposed to poisons. Data from the 1995 annual report of the American Association of Poison Control Centers Toxic Exposure Surveillance System show there were more than two million cases reported by 67 participating poison centers. ${ }^{3}$ Fifty three per cent of the cases occurred in children younger than 6 years of age. The two leading substances most frequently involved in this age group were cosmetics and personal care products, and cleaning substances.

Childhood poisonings are an important injury problem internationally. Due to the massive expansion in the use of chemicals, including pharmaceuticals and agrochemicals, many people are now at greater substantial risk for toxic exposures. ${ }^{4}$ Some items studied for their toxic effects on children throughout the world include caustic agents, ${ }^{5-7}$ camphorated oil,${ }^{8}$ and tobacco products. ${ }^{9}$

The use of prevention education to decrease childhood poisonings has long been advocated. National and international poison control or information centers have educated people about poison prevention. ${ }^{14}$ The messages delivered by these centers are highly dependent on the region's culture and the reasons for childhood poisoning, which vary substantially from country to country (R Soloway, Administrator, American Association of Poison Control Centers, personal communication, January 1998).

Since 1961 the President of the United States has designated the third week in March as National Poison Prevention Week, which has focused on preventing poisonings among preschool children. Hospitals, businesses, health agencies, poison centers, departments of health, and many other injury prevention groups reach out to children through interactive educational activities. ${ }^{2}$ Although education provided by various groups occurs year round in many states and local areas, there are few publications regarding the efficacy of these efforts. Some studies have examined how to educate parents, families, and adults, ${ }^{10-18}$ but little has been done to evaluate their effectiveness specifically for young children. Education has shown to increase preschool children's knowledge and understanding of poison prevention, ${ }^{19}$ but little formal evaluation has been done for programs targeted for older children. One recent international study did show that a community based mushroom poison prevention education program targeted for young schoolchildren led to increases in knowledge and decreases in intentions to practice unsafe behaviors related to eating wild mushrooms. ${ }^{20}$

The purpose of this study was to evaluate the MORE HEALTH poison prevention lesson delivered to kindergarten (age 5 or 6 years) and third grade students (age 8 or 9 years) throughout Hillsborough County, Florida. MORE HEALTH is a community health education program managed by a large urban hospital and sponsored by a coalition of organizations. Lessons are approximately 
Table 1 Kindergarten students: per cent correct post-test responses

\begin{tabular}{|c|c|c|c|c|}
\hline \multirow[b]{2}{*}{ Poison item } & \multicolumn{2}{|l|}{ Correct responses (\%) } & \multirow[b]{2}{*}{ Odds ratio } & \multirow[b]{2}{*}{$95 \% C I$} \\
\hline & Intervention $(n=84)$ & Control $(n=71)$ & & \\
\hline 1. What is a poison? & 84.5 & 49.3 & 5.6 & 2.5 to 12.8 \\
\hline 2. Where are poisons found? & 79.7 & 32.3 & 8.2 & 3.8 to 18.3 \\
\hline 3. Name some poisonous spiders & 7.1 & 0.0 & Undefined & - \\
\hline 4. Can you always tell which spiders are poisonous just by looking at them? & 54.7 & 35.2 & 2.2 & 1.1 to 4.5 \\
\hline 5. Name some poisonous snakes & 51.1 & 36.6 & 1.8 & 0.91 to 3.6 \\
\hline 6. Should you pick up a "strange" snake or a spider? & 100.0 & 91.5 & Undefined & - \\
\hline 7. What would you do if you were bitten by a spider or a snake? & 91.6 & 43.6 & 14.2 & 5.4 to 39.2 \\
\hline 8. If you're not sure if something is safe to eat or drink what should you do? & 91.6 & 57.7 & 8.0 & 3.0 to 22.2 \\
\hline 9. Should you ever take medicine without a grown-up present? & 100.0 & 87.3 & Undefined & - \\
\hline 10. Which one (props) is safe to eat or drink? & 94.0 & 47.8 & 17.2 & 5.9 to 59.7 \\
\hline 11. Show me how to do the stingray shuffle & 52.3 & 7.0 & 14.5 & 5.1 to 50.0 \\
\hline 12. Tell me what this is? (poison center telephone sticker) & 76.1 & 4.2 & 72.5 & 19.7 to 383.6 \\
\hline 13. Where are you supposed to put the sticker? & 94.0 & 9.8 & 144.5 & 39.2 to 579.1 \\
\hline
\end{tabular}

30-45 minutes in length, taught by well trained instructors, and include injury prevention. These poison prevention lessons reach approximately 6000 students per year. The goals of the kindergarten lesson are to have students identify poisonous substances and their locations, recognize poison lookalikes, and to "ALWAYS ASK FIRST" before touching or tasting unfamiliar substances. The goals of the third grade lesson are more complex, in that students are expected to be able to identify poisons in their environment, describe what to do in a poisoning emergency, and discuss how to poison-proof their homes.

\section{Methods}

The interactive 40 minute MORE HEALTH teaching session included prelesson materials for teachers-an "ALWAYS ASK FIRST" video for the kindergarten lesson, and a vocabulary list and books for the third grade lesson. For the kindergarten lesson, the instructor used singing, puppet shows, a story board, and poison lookalikes. For the third grade lesson, the instructor supplemented didactic instruction with class discussion, poison lookalikes, an experiment to demonstrate "invisible" gases, and opportunities for the children to act out scenarios of contacting the poison center. The students also discussed a poison proofing checklist and their responsibility to help poison-proof their homes. To reinforce what was discussed in class, kindergarten children were provided with materials to take home that included a poison center telephone sticker, a poison patrol badge, a letter to parents, and a brochure. Similar materials, including a magnet with the phone number of the poison center, were given to the third grade students. Also, posters of poisonous plants and snakes were distributed to participating schools.

The evaluation was based on a post-test only control group design. Three schools were selected to serve as evaluation sites and three others as control sites. The School Board required that their office and the MORE HEALTH Program choose the intervention and control schools. The agreed upon criteria for selection included schools that were representative of all socioeconomic levels and whose schedules permitted the researchers access to the classrooms.

Before the evaluation, two researchers reviewed videotapes of the lessons and attended actual presentations to confirm the instructor's fidelity to the lesson plan. All presentations were given by the same instructor. To assess the efficacy of the lessons, age appropriate questionnaires were developed based on a review of the literature. Questions included both forced choice and open ended items. Content validity was established by health educators experienced in survey design and poison prevention. Items were read aloud.

Interviews were administered one-on-one during times that created the least disruption. The same researcher conducted all interviews. She was introduced by the teacher and built

Table 2 Third grade students: per cent correct post-test responses

\begin{tabular}{|c|c|c|c|c|}
\hline \multirow[b]{2}{*}{ Poison item } & \multicolumn{2}{|l|}{ Correct responses (\%) } & \multirow[b]{2}{*}{ Odds ratio } & \multirow[b]{2}{*}{$95 \% C I$} \\
\hline & Intervention $(n=110)$ & Control ( $n=113)$ & & \\
\hline 1. What is a poison? & 95.4 & 70.8 & 8.7 & 3.1 to 29.4 \\
\hline 2. Where are poisons found? & 94.5 & 50.4 & 17.0 & 6.7 to 50.7 \\
\hline 3. Name some poisonous spiders & 75.4 & 6.1 & 46.6 & 18.1 to 124.9 \\
\hline 4. Can you always tell which spiders are poisonous just by looking at them? & 71.8 & 56.6 & 2.0 & 1.1 to 3.5 \\
\hline 5. Name some poisonous snakes & 66.3 & 39.8 & 3.0 & 1.7 to 5.4 \\
\hline 6. Should you pick up a "strange" snake or a spider? & 99.0 & 99.1 & 0.97 & 0.01 to 77.1 \\
\hline 7. What would you do if you were bitten by a spider or a snake? & 100.0 & 76.1 & Undefined & - \\
\hline 8. If you're not sure if something is safe to eat or drink what should you do? & 98.1 & 82.3 & 11.6 & 2.7 to 104.2 \\
\hline 9. Should you ever take medicine without a grown-up present? & 99.0 & 96.4 & 4.0 & 0.39 to 198.8 \\
\hline 10. Which one (props) is safe to eat or drink? & 97.2 & 76.9 & 10.7 & 3.1 to 56.3 \\
\hline 11. Show me how to do the stingray shuffle & 24.5 & 8.8 & 3.4 & 1.4 to 7.9 \\
\hline 12. Tell me what this is? (poison center telephone sticker) & 99.0 & 30.9 & 242.9 & 38.2 to 9800.7 \\
\hline 13. Where are you supposed to put the sticker? & 99.0 & 23.0 & 364.7 & 56.1 to 14694.8 \\
\hline 14. Do you know the different forms of poison? & 25.4 & 0.0 & Undefined & - \\
\hline 15. Do you know some ways a poison gets into the body? & 98.1 & 76.1 & 17.0 & 4.0 to 149.7 \\
\hline 16. Do you know how to make your home safer for your little brothers, sisters, or friends? & 89.0 & 22.1 & 28.8 & 12.9 to 65.4 \\
\hline 17. What would you do if a little brother or sister or friend was poisoned? & 100.0 & 77.8 & Undefined & - \\
\hline
\end{tabular}




\begin{tabular}{|c|c|c|}
\hline Poison item & $\begin{array}{l}\text { Kindergarten } \\
\text { parents }(\%)(n=35)\end{array}$ & $\begin{array}{l}\text { Third grade parents } \\
(\%)(n=42)\end{array}$ \\
\hline 1. Are all potentially harmful products stored behind locked cabinet doors or high and out of children's reach? & 62.8 & 76.1 \\
\hline 2. Are all harmful products stored away from food? & 94.2 & 97.6 \\
\hline 3. Are all potentially dangerous products stored in their original containers? & 100.0 & 97.6 \\
\hline 4. Are you sure there are no flaking paint chips on window sills, woodwork, playpens, or cribs? & 88.5 & 88.0 \\
\hline 5. Do you have syrup of ipecac in the house? & 31.4 & 40.4 \\
\hline 6. Have you thrown away all out of date prescriptions? & 82.8 & 88.0 \\
\hline 7. Have you identified all plants in and around your home so that you and your children know which are potentially toxic? & 60.0 & 66.6 \\
\hline 8. Do your vitamins, aspirins, and other medication have child resistant caps? & 94.2 & 88.0 \\
\hline 9. Do you have the poison center emergency phone number on or near the phone? & 85.7 & 73.8 \\
\hline
\end{tabular}

rapport before asking questions, to which the students responded orally. Each interview took approximately 10 minutes to complete. No students in the intervention or control groups had previous school based lessons that focused on poison prevention.

Interview topics included: (1) poison introduction (for example, "What is a poison?" and "Where are poisons found?"); (2) naming poisonous spiders and snakes and knowing what to do if bitten; (3) identification of poison lookalikes and whether to eat or drink lookalikes; (4) performance of the stingray shuffle (that is, students shuffle their feet to simulate what they would do in water to avoid being stung by a stingray); (5) knowing what the poison center telephone sticker is and where to place it in the home; (6) poison vocabulary (for third grade only: examples include knowing the forms of poisons and how poisons enter the body); and (7) how to make the home safe for younger brothers, sisters, or friends (third grade only).

The interview questions were pilot tested with kindergarten and third grade students at a school that was not part of the study to assess feasibility, timing, comprehension, and logistical issues. Post-test interviews were administered between one and two weeks after the intervention. A questionnaire was also developed for the parents of intervention children. This was included with the children's postlesson packet, with an accompanying letter asking parents to return the questionnaire to the teacher. Parents were asked if they took steps to make sure their homes were safe from various poisons, and if they were going to take additional steps after reviewing their child's take home materials. Questions focused on proper storage and disposal of harmful products, identification of poisonous plants, possession of syrup of ipecac, having the poison center emergency sticker on or near the telephone, description of any poisoning incidents in the home reported to the poison center, and perception of the quality of the center's response.

All children and parents were informed that their participation was voluntary and that confidentiality would be maintained. No children refused to be interviewed. The project was approved by the University's Review Board and the School System. Data analysis included frequencies, descriptive statistics, and calculations of the odds ratio and $95 \%$ confidence interval (CI) to determine the odds of answering questions correctly based on being in an intervention or control group. Exact upper and lower limits were calculated in instances where Cornfield $95 \%$ confidence limits were not accurate.

\section{Results}

One hundred ninety four intervention children and 184 control children were studied: 84 intervention and 71 control kindergarten children and 110 intervention and 113 control third grade children. Intervention children consistently answered more questions correctly than children who were part of the control groups (tables 1 and 2).

To determine the probability of children answering questions correctly in the two groups, we computed the odds ratio and corresponding 95\% CI. The differences for kindergarten children were statistically significant for all items for which odds ratios could be computed except one (naming poisonous snakes). For the third grade children, differences were statistically significant for all but two items-picking up strange snakes or spiders and not taking medicine without an adult present.

Seventy seven intervention school parents $(39.7 \%)$ returned the questionnaire. Table 3 shows selected responses of kindergarten and third grade parents. The majority of parents reported that their homes were poison-proof and the only item where fewer than $50 \%$ of the parents responded correctly was having syrup of ipecac available. Ten parents reported having to contact the poison center about a poisoning incident and all reported that the center responded to their satisfaction.

\section{Discussion}

To our knowledge, this study is one of the very few examples of an evaluation of a poison prevention lesson aimed at children in the primary grades and results show that this intervention changed knowledge significantly for both grade levels studied. Key concepts, such as the identification and placement of poison center stickers with emergency telephone numbers, can be communicated effectively to young children. This may be particularly important to the success of community-wide education campaigns because schools can serve as important conduits for prevention messages.

Though the results generally support the intervention, not all concepts were absorbed uniformly. For example, in the kindergarten group, children did not retain information about poisonous spiders. In addition, some 
questions may have been "too easy" to test true gains in knowledge. All children in kindergarten showed knowledge about avoiding contact with "strange" snakes and spiders, and not taking medicines without adult supervision.

A similar situation applies to the third grade results. All of the intervention group correctly identified the proper protocol to follow if bitten by a snake or spider, as did $76 \%$ of the control group. All intervention subjects knew what to do if a sibling was poisoned, as did nearly $78 \%$ of controls. The third grade program's major shortcoming appeared to be its inability to communicate the various forms in which poisons exist (for example, gas, liquid, solid, etc). However, at post-test, more than $25 \%$ of the intervention subjects answered the item correctly, compared with none of the controls.

\section{Study limitations}

Because of the requirements of the school system, it was not possible to randomize the schools. However, the post-test only control group design eliminates the effects of pretesting as a confounding factor in interpreting results, ${ }^{21}$ and decreases the labor intensity of the evaluation effort. ${ }^{22}$ Although complete equivalence of the intervention and control groups before the intervention cannot be guaranteed with this design, the assumption of equivalence is not an unreasonable one, given the age of the children and the documented absence of formal school based education efforts. It was not possible to do second interviews to determine if knowledge was retained. Most importantly, we were unable to study the children's behavior to see if their knowledge translated into action. However, an unpublished study from Georgia suggests that a similar curriculum significantly changed children's knowledge, attitudes, and practices regarding poison safety (Paige Cucchi, Georgia Poison Center, personal communication, July 1997). In addition, it has been shown that increases in knowledge significantly contribute to intention to use poison prevention behaviors. ${ }^{20}$

The results of our study may not be generalizable to other groups and settings. However, they are indicative of the potential for early intervention programs to stimulate awareness among children and their parents.

For school based poison prevention programs to improve and expand, it is recommended that lessons be incorporated into other subject areas and that parent communication occurs. In addition, it is important that schools partner with community injury prevention groups and poison centers. Programs devel- oped and implemented need to be evaluated for accountability, improvement, and decision making. ${ }^{23}$ There is a need for future research studies to determine, through randomized controlled trials, if and how education for young children significantly contributes to behavior change and decreases in poison related morbidity and mortality.

The project was funded by the Florida Poison Information and Toxicology Resource Center at Tampa General Hospital.

1 Wilson MH, Baker SP, Teret SP, et al. Saving children-a guide to injury prevention. New York: Oxford University Press, 1991: 100.

2 Poison Prevention Week Council. Report on national poison prevention week. Washington, DC: Poison Prevention Week Council, 1997.

3 Litovitz TL, Felberg L, White S, et al. 1995 Annual report of the American Association of Poison Control Centers Toxic Exposure Surveillance System. Am f Emerg Med 1996;14: 487-537.

4 Berger LR, Mohan D. Injury control - a global view. New Dehli, India: Oxford University Press, 1996: 189-90.

5 Christesen HB. Epidemiology and prevention of caustic ingestion in children. Acta Paediatr 1994;83:212-5.

6 Clausen JO, Nielsen TL, Fogh A. Admission to Danish hospitals after suspected ingestion of corrosives. A nationwide survey (1984-1988) comprising children aged 0-14 years. Dan Med Bull 1994;41:234-7.

7 Nuutinen $M$, Uhari $M$, Karvali $T$, et al. Consequences of caustic ingestions in children [review]. Acta Paediatr 1994; 83:1200-5.

8 Theis JG, Koren G. Camphorated oil: still endangering the lives of Canadian children. Can Med Assoc 7 1995;152: 1821-4.

9 Akahori F, Shintani S. The status and future of toxicology in Japan and the Pacific Rim. Vet Human Toxicol 1994;36:14451 .

10 Brannan JE. Accidental poisoning of children: barriers to esource use in a black, low-income community. Public Health Nurs 1992;9:81-6.

11 Krenzelok EP. The use of poison prevention and education strategies to enhance the awareness of the poison information center and to prevent accidental poisonings. Clin Toxicol 1995;33:663-7.

12 Woolf A, Lewander W, Filippone G, et al. Prevention of childhood poisoning: efficacy of an educational program carried out in an emergency clinic. Pediatrics 1987;80:35963.

13 Dershewitz RA, Williamson JW. Prevention of childhood household injuries: a controlled clinical trial. Am f Public Health 1977;67:1148-53.

14 Fergusson DM, Horwood LJ, Beautrais AL, et al. A controlled field trial of a poisoning prevention method. Pediatrics 1982;69:515-20.

15 Rey S, Courtois X, Zmirou D, et al. [Evaluation of an educational action on accident prevention in children]. Pediatrie 1993;48:727-33.

16 Cooper JM, Widness JA, O'Shea JS. Pilot evaluation of instructing parents of newborns about poison prevention strategies. Am $\mathcal{F}$ Dis Child 1988;142:627-9.

17 Harris DW, Karandikar DS, Spencer MG, et al. Returnedmedicines campaign in Birmingham, 1977. Lancet 1979;i: 599-601.

18 O'Connor PJ. Poisoning prevention: results of a public media campaign. Aust Paediatr F 1982;18:250-2.

19 Krenzelok EP, Garber RJ. Teaching poison prevention to preschool children, their parents, and professional educators through child care centers. Am $\mathcal{f}$ Public Health 1981;71:750-2.

20 Malinowska-Cieslik M, Borne B. Prevention of mushroom poisoning of children: effectiveness of a community-based school education programme. Health Educ Res 1998;13:1323.

21 Campbell DT, Stanley JC. Experimental and quasiexperimental designs for research. Boston: Houghton Mifflin

22 Sarvela PD, McDermott RJ. Health education and measurement, a practitioner's perspective. Madison, WI: Brown and Benchmark, 1993.

23 Vincenten J. Program evaluation for prevention projects. Inj Prev 1997;3:124-5. 